\title{
POLÍTICA EDUCACIONAL NO BRASIL APÓS A DITADURA
} MILITAR

Dermeval Saviani ${ }^{1}$

\section{Resumo}

Partindo do contex to caracterizado pelo denominado "Consenso de Washington", este artigo aborda a política educacional no período pós ditadura militar analisando as iniciativas dos governos de Sarney, Collor, Itamar, FHC, Lula e Dilma, concluindo com uma referência ao atual governo Temer decorrente do golpe que destituiu a Presidenta reeleita.

Palavras-chave: Educação brasileira. Política educacional. Política educacional no Brasil.

\section{EDUCATIONAL POLICY IN BRAZIL AFTER THE MILITARY DICTATORSHIP}

\begin{abstract}
From the context of the so-called "Washington Consensus", this article deals with educational policy in the period after the military dictatorship, analyzing the initiatives of the governments of Sarney, Collor, Itamar, FHC, Lula and Dilma, concluding with a reference to the current Temer government that resulted of the coup that deposed the reelected President.
\end{abstract}

Keywords: Brazilian education. Educational politics. Educational policy in Brazil.

\section{POLÍTICA EDUCACIONAL EN BRASIL DESPUÉS DE LA DITADURA MILITAR}

\section{Resumen}

En el marco del contexto caracterizado por el denominado "Consenso de Washington", este artículo aborda la política educativa en el período post dictadura militar analizando las iniciativas de los gobiernos de Sarney, Collor, Itamar, FHC, Lula y Dilma, concluyendo con una referencia al actual gobierno Temer derivado del golpe que destituyó a la presidenta reelecta.

Palabras clave: Educación brasileña. Política educativa. Política educativa en Brasil. 


\section{Revista HIISTESIDBR On-lime}

ISSN: $1676-2584$

Debates

doi: 10.20396/rho.v18i2.8652795

\section{TRANSIÇÃO DEMOCRÁTICA E INSERÇÃO DO BRASIL NA NOVA ORDEM MUNDIAL: O CONSENSO DE WASHINGTON}

A transição que se operou no Brasil entre a ditadura implantada mediante golpe militar em 1964 e o regime democrático se iniciou com a "distensão lenta, gradual e segura" formulada em 1974 no governo do general Ernesto Geisel por inspiração do General Golbery do Couto e Silva, eminência parda do regime militar; e prosseguiu na "abertura democrática" a partir de 1979 com a "Lei da Anistia" ( Lei n 6.683, de 28 de agosto de 1979) no governo do general João Batista de Oliveira Figueiredo, desembocando na "Nova República" em 1985, que guindou à posição de Presidente da República o ex-presidente do partido de sustentação do regime militar uma vez que Tancredo Neves, eleito pelo Colégio Eleitoral, veio a falecer ainda antes de tomar posse. A "transição democrática" se fez, pois, segundo a estratégia da conciliação pelo alto, visando a garantir a continuidade da ordem socioeconômica em consonância, portanto, com a visão dos grupos dominantes, à frente a burguesia, que interpretam a "transição democrática" na linha da estratégia da conciliação, reduzindo-a a um mecanismo de preservação, numa forma que incorpora o consentimento dos dominados, dos próprios privilégios.

Em contrapartida, os grupos dominados, em especial o proletariado, veem a "transição democrática" como um processo de libertação de sua condição de dominados. Portanto, conforme os interesses dominados, a transição só poderia ser feita por ruptura decorrente da luta por uma forma de democracia que assegurasse "[...] à massa popular dos mais ou menos espoliados e excluídos e aos trabalhadores como classe o direito à revolução (dentro da ordem e contra a ordem)." (FERNANDES, 1986, p. 89). Ocultando essa diferença a expressão "transição democrática" acaba por desempenhar o papel de camuflar os antagonismos entre as classes sociais fundamentais, abrindo espaço para a obtenção do consentimento dos dominados à transição conservadora transacionada pelas elites dirigentes.

A nova ordem socioeconômica então instaurada recebeu o nome de "neoliberalismo" que remete ao "Consenso de Washington". Essa expressão decorreu da reunião promovida em 1989 por John Williamson no International Institute for Economy, que funciona em Washington, com o objetivo de discutir as reformas consideradas necessárias para a América Latina. Os resultados dessa reunião foram publicados em 1990. Williamson denominou de "Consenso de Washington" o conjunto das recomendações saídas da reunião porque teria constatado que se tratava de pontos que gozavam de certa unanimidade, ou seja, as reformas sugeridas eram reclamadas pelos vários organismos internacionais e pelos intelectuais que atuavam nos diversos institutos de economia. Ora, essa constatação reflete os rumos tomados pela política mundial após a ascensão de Margaret Thatcher, na Inglaterra, que governou entre 1979 e 1990, e de Ronald Reagan, nos Estados Unidos, cujo governo se estendeu de 1981 a 1989. Tais governos, assim como o de Helmut Kohl², que governou a Alemanha entre 1982 e 1998, representavam a posição conservadora nos respectivos países e se instauraram 
sob o signo do ultra liberalismo de Hayek e do monetarismo de Milton Friedman, cujo prestígio na década de 1970 pode ser aferido pela obtenção do prêmio Nobel de economia em 1974 e 1976, respectivamente.

Esse novo pensamento hegemônico convergia em torno de um denominador comum: "[...] o ataque ao estado regulador e a defesa do retorno ao estado liberal idealizado pelos clássicos." (FIORI, 1998, p. 116). Ainda segundo Fiori, a reordenação empreendida implicou, no campo econômico, a elevação ao status de valor universal de políticas como o equilíbrio fiscal, a desregulação dos mercados, a abertura das economias nacionais e a privatização dos serviços públicos; no campo político, a crítica às democracias de massa (FIORI, 1998).

No que se refere à América Latina o consenso implicava, em primeiro lugar, um programa de rigoroso equilíbrio fiscal a ser conseguido por meio de reformas administrativas, trabalhistas e previdenciárias tendo como vetor um corte profundo nos gastos públicos. Em segundo lugar, impunha-se uma rígida política monetária, visando à estabilização. Em terceiro lugar, a desregulação dos mercados tanto financeiro como do trabalho, privatização radical e abertura comercial. Essas políticas que inicialmente tiveram que ser, de algum modo, impostas pelas agências internacionais de financiamento mediante as chamadas condicionalidades, em seguida perdem o caráter de imposição, pois são assumidas pelas próprias elites econômicas e políticas dos países latino-americanos.

Nesse novo contexto as medidas de política educacional vão ser marcadas por uma espécie de neoconservadorismo. Diante do mote do "Estado mínimo" passa-se a considerar a chamada "decadência da escola pública" como resultado da incapacidade do Estado de gerir o bem comum. Com isso advoga-se, também no âmbito da educação, a primazia da iniciativa privada regida pelas leis do mercado.

\section{O CONTEXTO DO FINAL DA DITADURA E A POLÍtica EDUCACIONAL}

O campo dos profissionais da educação veio, desde o final da década de 1970, lutando para superar os limites da política educacional da Ditadura Militar com a mobilização da ANPEd (Associação Nacional de Pesquisa e Pós-Graduação em Educação), fundada em 1977; do CEDES (Centro de Estudos Educação e Sociedade), cuja fundação foi articulada em 1978 e formalizada em março de 1979; da ANDE (Associação Nacional de Educação), fundada em 1979; da CPB (Confederação dos Professores do Brasil), constituída em 1979 a partir da CPPB (Confederação dos Professores Primários do Brasil), criada em 1960; da CNTE (Confederação Nacional dos Trabalhadores da Educação), na qual se transformou a CPB em 1989; da ANDES (Associação Nacional dos Docentes do Ensino 
Superior), criada em 1981; além da FASUBRA (Federação das Associações de Servidores das Universidades Públicas), criada em 1978.

Como expressão dessa mobilização os educadores organizaram a série das Conferências Brasileiras de Educação (CBEs), inaugurada em 1980 aprofundando, com essa iniciativa, a discussão da política educacional e procurando interferir no seu encaminhamento, o que pode ser aferido pela definição do tema central de cada uma das CBEs:

I CBE (1980), tema central: A política educacional;

II CBE (1982): Educação: perspectiva na democratização da sociedade;

III CBE (1984): Da crítica às propostas de ação;

IV CBE (1986): A educação e a Constituinte;

V CBE (1988): A lei de diretrizes e bases da educação nacional;

VI CBE (1991): Política Nacional de Educação.

Seguindo nessa linha de procurar intervir na formulação da política educacional, os educadores chegaram a apresentar um projeto da Lei de Diretrizes e Bases da Educação Nacional que, antecipando-se ao governo, foi protocolado na Câmara dos Deputados sob número 1.158-A/88 em dezembro de 1988 embora, ao final, tenha sido derrotado pela interferência do governo FHC no Senado. Igualmente, após a aprovação da LDB, os profissionais da educação reunidos no I e II CONEDs (Congressos Nacionais de Educação), realizados respectivamente em agosto e novembro de 1997, ambos em Belo Horizonte, elaboraram o projeto de PNE (Plano Nacional de Educação) conhecido como "projeto da sociedade brasileira", que também se antecipou ao governo dando entrada na Câmara dos Deputados em 10 de fevereiro de 1998 sendo seguido, dois dias depois, do projeto do MEC que, embora apensado ao anterior, teve a prioridade invertida porque o governo tinha maioria no congresso e reverteu a iniciativa dos educadores. Enfim, de modo especial a partir do segundo mandato de Lula o protagonismo dos educadores tornou-se mais efetivo logrando vários avanços convergindo para a I e II CONAEs (Conferências Nacionais de Educação) tendo como tema central a construção do Sistema Nacional de Educação e do novo Plano Nacional de Educação.

A forte mobilização dos educadores no final dos anos de 1970 e nos anos 1980 não logrou, porém, converter suas propostas em política educacional no âmbito governamental. A chamada Nova República presidida por José Sarney com a instalação de um governo civil, em 1985, nas eleições do Colégio Eleitoral, caracterizou-se pelo democratismo, indefinições e ambiguidades.

\section{AS POLÍTICAS EDUCACIONAIS DOS GOVERNOS PÓS- CONSTITUIÇÃO DE 1988}




\section{Revista HIIST'TEIDBR On-line}

ISSN: 1676-2584

Debates

doi: 10.20396/rho.v18i2.8652795

\section{a) INICIATIVAS DO GOVERNO COLLOR-ITAMAR}

Ocorridas as primeiras eleições diretas para Presidente da República, em 1989, assumiu, em 15 de março de 1990, Fernando Collor de Mello em cujo mandato foi lançado o Programa Nacional de Alfabetização e Cidadania e os CIACs (Centros Integrais de Atenção à Criança), apelidados de "os CIEPs colloridos" porque resultaram de uma adaptação dos CIEPs instalados no Rio de Janeiro no governo de Leonel Brizola, como testemunhou o próprio Darcy Ribeiro. Em entrevista concedida à Revista Presença Pedagógica no início de 1996, ele afirma: "O Brizola convence o Collor de fazer dez mil Cieps. O Collor resolve fazer cinco mil, mas pede que não sejam iguais aos de Niemeyer. Pegamos, então, os planos de Minas e foram construídos os Ciacs. O projeto que fiz cuidadosamente para Minas, foi adotado pelo Collor." (RIBEIRO, 1996, p. 12). Ambos esses programas não foram implementados. A política educacional do governo Collor resumiu-se a arbitrar sobre os preços das mensalidades das escolas privadas.

Destituído da presidência por meio de um processo de impeachment, Collor foi substituído pelo vice-presidente, Itamar Franco, em outubro de 1992. Durante seu governo foi lançado, em 1993, o Plano Decenal "Educação para todos" inspirado na Declaração "Educação para Todos" da Conferência de Jontien, Tailândia, de 1991. Esse plano estava focado no ensino fundamental e se propunha, em dez anos, atingir o duplo objetivo fixado na Constituição: Eliminar o analfabetismo e universalizar o ensino fundamental (Art. 60 das Disposições Transitórias).

A outra realização do Governo Itamar, gestão de Murílio Hingel, foi o fechamento do Conselho Federal de Educação e criação do Conselho Nacional de Educação. De fato, com as reformas educacionais do regime militar o Conselho Federal de Educação passou a desempenhar função central na elaboração e no direcionamento da política educacional. Como sua composição previa a representação das escolas particulares, esses órgãos passaram a ser alvos de poderosos lobbys visando a influenciar as decisões no sentido do favorecimento de seus interesses. A ousadia dos lobistas chegou ao ponto do envolvimento em corrupção, o que levou ao fechamento do Conselho Federal de Educação em 1994 na gestão de Murílio Hingel como ministro da educação. Dessa forma, pela Medida Provisória n. 661, de 18 de outubro de 1994, foi instituído o Conselho Nacional de Educação em substituição ao CFE, cujos membros tiveram seus mandatos extintos.

\section{b) INICIATIVAS DO GOVERNO FHC}

No ano seguinte o funcionamento do Conselho Nacional de Educação (CNE) foi regulado pela Lei n. 9.131, de 24 de novembro de 1995, portanto, já no mandato de Paulo Renato Costa Souza como Ministro da Educação do Governo FHC. Essa lei, tendo como ementa "altera dispositivos da Lei n. 4.024, de 20 de dezembro de 1961, e dá outras providências", redefiniu o papel do MEC na educação do país, regulamentando por 


\section{Revista HIISTEYIDIR On-line}

antecipação o que veio a ser disposto nos artigos $8^{\circ}$ e $9^{\circ}$ da nova LDB. Ao instituir e regular o CNE pela alteração dos artigos $7^{\circ}, 8^{\circ}$ e $9^{\circ}$ da LDB anterior, regulamentou, também por antecipação, o parágrafo $1^{\circ}$ do artigo $9^{\circ}$ da nova LDB no qual se determinou a existência do Conselho Nacional de Educação. Pelos artigos $3^{\circ}$ e $4^{\circ}$ dão-se as outras providências, isto é, são instituídos os exames nacionais de cursos de nível superior ("provão") que, de acordo com o previsto no parágrafo $7^{\circ}$ do artigo $3^{\circ}$, seriam efetuados gradativamente a partir do ano seguinte à publicação da lei. De fato, em 1996 foram realizados os primeiros exames nacionais, cujos resultados evidenciaram o baixo nível, em média, dos cursos das instituições privadas comparativamente ao ensino superior público. Diante do que ficou evidenciado pelos exames nacionais de cursos, o MEC acenou com a abertura de uma linha de crédito de 300 milhões de reais para financiar programas de melhoria da qualidade dos cursos das escolas particulares, o que mereceu um editorial por parte da, nesse caso, insuspeita Folha de S. Paulo, na edição de 15 de março de 1997, condenando essa iniciativa por estar premiando a incompetência em lugar de proceder à punição das escolas pelo seu fraco desempenho qualitativo. (PUNIR..., 1997, p. 1). O artigo $5^{\circ}$ revogou as atribuições e competências do extinto Conselho Federal de Educação. Pelo artigo $6^{\circ}$ foram extintos os mandatos dos membros do CFE, passando o MEC a exercer as atribuições do CNE, que, de acordo com o parágrafo único desse mesmo artigo, deveria ser instalado no prazo de noventa dias a contar da publicação da lei em referência. $\mathrm{O}$ artigo $7^{\circ}$ convalidou os atos praticados com base na Medida Provisória n. 1.126, de 26 de setembro de 1995, determinando que os processos em andamento fossem objeto de decisão do CNE, uma vez este instalado, mediante solicitação da parte interessada que deveria ser efetuada no prazo de trinta dias a partir da vigência da lei.

Não havia se passado ainda um mês da aprovação da Lei 9.131 e uma nova lei foi editada. Trata-se da Lei n. 9.192, de 21 de dezembro de 1995, que estabeleceu regras comuns para a escolha dos dirigentes universitários. Destaca-se, aí, a exigência de se observar, para a composição dos colegiados universitários, "o mínimo de setenta por cento de membros do corpo docente no total de sua composição". Regulamentando essa lei, o Decreto n. 1.916, de 23 de maio de 1996, completou a normatização do processo de escolha dos dirigentes das instituições federais de ensino superior. E também a avaliação das instituições de ensino superior, prevista na Lei n. 9.131, de 24 de novembro de 1995, foi regulamentada pelo Decreto n. 2.026, baixado em 10 de outubro de 1996. Vê-se que todas essas medidas foram tomadas ainda antes da aprovação da LDB, sendo que várias delas desempenharam o papel de regulamentar por antecipação a própria LDB. Enquanto por esse meio ia implementando sua política educacional, o governo FHC buscou interferir na tramitação da LDB logrando fazer aprovar uma lei minimalista que desobriga a União da manutenção da educação, mas concentra nela a avaliação.

Em 15 de abril de 1997 foi editado o Decreto n. 2.207, revogado e substituído pelo Decreto n. 2.306, de 19 de agosto de 1997, regulamentando os dispositivos da nova LDB 


\section{Revista HIISTEYIDIR On-line}

referentes ao ensino superior. Desse decreto importa destacar dois aspectos sendo, o primeiro, a admissão aberta e franca das instituições educacionais com fins lucrativos; e o segundo diz respeito à introdução, na classificação acadêmica das instituições de ensino superior, da distinção entre "universidades" e "centros universitários".

Em verdade, os centros universitários são um eufemismo das universidades de ensino, isto é, uma universidade de segunda classe, que não necessita desenvolver pesquisa, enquanto alternativa buscada pelo governo FHC para viabilizar a expansão e, por consequência, a "democratização" da universidade a baixo custo, em contraposição a um pequeno número de centros de excelência, isto é, as "universidades de pesquisa", que concentrariam o grosso dos investimentos públicos, acentuando o seu caráter elitista. De fato, a expressão "centros universitários" foi a fórmula encontrada para burlar o artigo 207 da Constituição Federal, que afirma que as universidades “[...] obedecerão ao princípio da indissociabilidade entre ensino, pesquisa e extensão”. (BRASIL, 1988, s. 1).

Em 9 de julho de 2001, portanto já no último ano do Governo FHC, foi editado o Decreto n. 3.860 que substituiu os Decretos n. 2.026 e n. 2.306. O teor do novo decreto é fundamentalmente o mesmo dos dois anteriores, cujo conteúdo é consolidado e mais bem ordenado, procedendo-se a pequenos ajustes. Tendo como ementa "Dispõe sobre a organização do ensino superior, a avaliação de cursos e instituições, e dá outras providências", o referido decreto foi estruturado em 41 artigos dispostos em cinco capítulos: I - "Da Classificação das Instituições de Ensino Superior"; II - "Das Entidades Mantenedoras"; III - "Das Instituições de Ensino Superior"; IV - "Da Avaliação"; V - "Dos Procedimentos Operacionais".

Outra frente de atuação do governo federal na formulação e implementação da política educacional refere-se ao ensino fundamental e também se iniciou antes da aprovação da nova LDB. A principal investida deu-se no que diz respeito à questão do financiamento desse grau de ensino, o que resultou na criação do FUNDEF (Fundo de Manutenção e Desenvolvimento do Ensino Fundamental e de Valorização do Magistério), efetivada por meio da Emenda Constitucional n. 14, de 12 de setembro de 1996, regulamentada pela Lei n. 9.424, promulgada em 24 de dezembro de 1996, portanto, um dia após a publicação da nova LDB.

No que se refere à formação profissional, a marca do Governo FHC foi a separação entre ensino médio e ensino técnico-profissional determinada pelo Decreto $\mathrm{n}^{\circ} 2.208$, de 17 de abril de 1997. Tal medida significou voltar atrás no tempo, não apenas em relação à Lei n. 5.692 de 1971, mas em relação à LDB de 1961, já que esta flexibilizou a relação entre os ramos do ensino médio de então, permitindo a equivalência e o trânsito entre eles, quebrando, assim, a "dualidade de sistemas" própria das reformas Capanema da década de 1940, na vigência do Estado Novo. Ora, é a essa dualidade que se retornou com o referido decreto. 


\section{Revista HIISTEYIDIR On-line}

Mas a medida de maior impacto da política educacional do Governo FHC foi certamente a montagem do sistema nacional de avaliação por meio da Medida Provisória ${ }^{\circ}$ 1.568, editada em 14 de fevereiro de 1997 que, aprovada pelo Congresso, converteu-se na Lei no 9.448, de 14 de março de 1997, transformando o INEP em Autarquia Federal, como se pode ver pelo artigo $1^{\circ}$ que também redefine suas funções:

Art. $1^{\circ}$ Fica o Instituto Nacional de Estudos e Pesquisas Educacionais - INEP, órgão integrante da estrutura do Ministério da Educação e do Desporto, transformado em Autarquia Federal vinculada àquele Ministério, com sede e foro na cidade de Brasília - DF, tendo como finalidades:

I - Organizar e manter o sistema de informações e estatísticas educacionais;

II - Planejar, orientar e coordenar o desenvolvimento de sistemas e projetos de avaliação educacional, visando o estabelecimento de indicadores de desempenho das atividades de ensino no País;

III - Apoiar os Estados, o Distrito Federal e os Municípios no desenvolvimento de sistemas e projetos de avaliação educacional;

IV - Desenvolver e implementar, na área educacional, sistemas de informação e documentação que abranjam estatísticas, avaliações educacionais, práticas pedagógicas e de gestão das políticas educacionais;

V - Subsidiar a formulação de políticas na área de educação, mediante a elaboração de diagnósticos e recomendações decorrentes da avaliação da educação básica e superior;

VI - Coordenar o processo de avaliação dos cursos de graduação, em conformidade com a legislação vigente;

VII - Definir e propor parâmetros, critérios e mecanismos para a realização de exames de acesso ao ensino superior;

VIII - Promover a disseminação de informações sobre avaliação da educação básica e superior;

IX - Articular-se, em sua área de atuação, com instituições nacionais, estrangeiras e internacionais, mediante ações de cooperação institucional, técnica e financeira bilateral e multilateral. (BRASIL, 1997, p. 1).

Pelo enunciado das atribuições vê-se que o INEP deixou de ser um órgão de realização e fomento à pesquisa educacional, de organização da documentação sobre educação e de disseminação das informações educacionais, funções que lhe foram atribuídas desde sua fundação até a promulgação dessa lei, para se converter num órgão de avaliação da educação brasileira em todos os seus níveis e modalidades. Foi, de fato, uma verdadeira refundação, como definiu sua presidente reempossada, Maria Helena Guimarães de Castro.

Consolidou-se, em consequência, o SAEB (Sistema de Avaliação da Educação Básica), que ficou sob gestão do INEP e instituiu-se, em 1998, o ENEM (Exame Nacional do Ensino Médio), também gerenciado pelo INEP.

E a política educacional do Governo FHC se completa com a entrada na Câmara dos Deputados do projeto do PNE, o PL n. 4.173/98, em 12/2/1998, apensado ao projeto da oposição, PL n. 4.155/98, de 10/2/1998 e convertido na Lei no 10.172, de 9/1/2001, que instituiu o Plano Nacional de Educação.

\section{c) INICIATIVAS DO GOVERNO LULA}




\section{Revista HIISTEYIDIR On-line}

Ao longo do primeiro mandato do Governo Lula, transcorrido entre $1^{\circ}$ de janeiro de 2003 e 31 de dezembro de 2006, foram tomadas novas medidas no que se refere ao papel da União na organização da educação nacional. Entre essas medidas destacam-se a Lei $\mathrm{n}$. 10.861, de 14 de abril de 2004, que criou o SINAES (Sistema Nacional de Avaliação da Educação Superior e o ENADE (Exame Nacional de Desempenho dos Estudantes); o Decreto n. 5.773, de 9 de maio de 2006, que regulamentou a implantação do SINAES e do ENADE; a Lei n. 11.096, de 13 de janeiro de 2005, que criou o PROUNI (Programa Universidade para Todos); e o Decreto n. 5.493, de 18 de julho de 2005, que regulamentou a implantação do PROUNI.

Essas medidas se ligam à regulação do nível federal e, basicamente, ao ensino superior com destaque para a avaliação. Como tais, não chegaram a alterar o espírito que presidiu a política educacional do governo anterior. Ao contrário, deram continuidade mantendo o INEP como órgão gestor do sistema de avaliação, sendo que a substituição do "provão" pelo ENADE incidiu apenas em aspectos operacionais. E a própria criação do PROUNI, embora se constituindo numa inovação, não só não se opõe à orientação do Governo FHC como a reforça, pois esse governo se empenhava em ampliar a participação das instituições privadas na oferta de vagas do ensino superior.

Ainda no primeiro mandato registra-se a aprovação da Lei n ${ }^{\circ} 11.114$, de 16/5/2005, que antecipou o início do Ensino Fundamental para os 9 anos de idade, o que foi ratificado pela Lei $\mathrm{n}^{\mathrm{o}} 11.274$, de 6/2/2006, instituindo o ensino fundamental de 9 anos. E no apagar das luzes desse primeiro mandato, já eleito para o segundo, em razão do vencimento do prazo de vigência do FUNDEF, foi aprovada, em 19 de dezembro de 2006, a Emenda Constitucional n. 53 e baixada a Medida Provisória n. 339, em 29 de dezembro de 2006, convertida, já no segunda mandato, na Lei $\mathrm{n}^{\circ} 11.494$, de 20/6/2007, regulamentada pelo Decreto $^{\mathrm{o}} 6.253$, de 13/11/2007, modificado pelo Decreto ${ }^{\circ} 6.278$, de 29/11/2007. Por meio desses dispositivos legais foi criado, em substituição ao FUNDEF, o Fundo de Manutenção e Desenvolvimento da Educação Básica e de Valorização dos Profissionais da Educação (FUNDEB) que significou um importante avanço em relação ao fundo anterior, pois ampliou sua abrangência para toda a educação básica. Assim, o Fundo passou a incluir, além do ensino fundamental, também a educação infantil (creches e pré--escolas), o ensino médio e a educação de jovens e adultos (EJA), abrangendo os meios urbano e rural e as modalidades da educação especial, da educação indígena e quilombola, assim como a educação profissional integrada ao ensino médio. E buscou ampliar e tornar efetivo o compromisso da União com o financiamento da educação básica ao incluir na Medida Provisória n. 339 um dispositivo vedando à instância federal a utilização do salário-educação para suprir a sua parte na composição do Fundo, diferentemente do que fazia o Governo FHC.

Nesse início do segundo mandato o Governo Lula se diferenciou mais nitidamente da chamada "Era FHC" ao instituir o Plano de Desenvolvimento da Educação (PDE) por meio de um conjunto de decretos baixados em 24 de abril de 2007. Tendo como carro-chefe 
o Decreto n. 6.094, que dispôs sobre o "Plano de Metas Compromisso Todos pela Educação", na mesma data foram editados os decretos n. 6093, sobre a reorganização do Programa Brasil Alfabetizado; n. 6.095, sobre o processo de integração de instituições federais de educação tecnológica; e n. 6.096, que instituiu o PROUNI. Também no âmbito do PDE foram editadas, em 16 de julho de 2007, a Lei n. 11.738, que instituiu o "piso salarial profissional para os profissionais do magistério público da educação básica" e, em 25 de setembro de 2008, a Lei n. 11.788, dispondo sobre a regulamentação dos estágios dos estudantes das "instituições de educação superior, de educação profissional, de ensino médio, da educação especial e dos anos finais do ensino fundamental, na modalidade profissional da educação de jovens e adultos". Uma análise mais desenvolvida dessa problemática o leitor pode encontrar no livro PDE - Plano de Desenvolvimento da Educação: análise crítica da política do MEC (SAVIANI, 2009) no qual também encontrará, como anexos, o teor integral dos seis dispositivos legais citados que compõem o PDE.

Como se pode ver, dois dos dispositivos legais acima citados, no âmbito do PDE, dizem respeito à formação profissional. São eles o Decreto ${ }^{\circ} 6.095$, de 24/4/2007, que fixou as diretrizes para integração de instituições federais de educação tecnológica tendo em vista a constituição dos Institutos Federais de Educação, Ciência e Tecnologia no âmbito da Rede Federal de Educação Tecnológica e a Lei n. 11.788, de 35 de setembro de 2008, que regulamentou os estágios. Efetivamente, essa é uma área na qual o Governo Lula se contrapôs, desde o primeiro mandato, ao Governo FHC. Levando em conta as críticas que os estudiosos da área de educação e trabalho formularam ao Decreto n. 2.208, baixado em 17 de abril de 1997 pelo Governo anterior, o Governo Lula editou, em 23 de julho de 2004, o Decreto n. 5.154 que, em seu último artigo, estabelece taxativamente: Revoga-se o Decreto n. 2.208, de 17 de abril de 1997 (artigo 9 ${ }^{\circ}$ ). Com esse novo decreto retoma-se a tendência da formação integrada visando à superação da dualidade entre educação geral e formação profissional, revertendo o retrocesso representado pelo decreto do Governo FHC.

\section{d) INICIATIVAS DO GOVERNO DILMA}

O Governo Dilma deu continuidade à política educacional do Governo Lula efetuando alterações pontuais em aspectos da LDB como a inclusão do $\S 3^{\circ}$ no Art. 79 da Lei n. 12.416, de 9 de junho de 2011, referente à oferta de educação superior para os povos indígenas; acréscimo do $\S 7^{\circ}$ ao artigo 26 incluindo nos currículos do ensino fundamental e ensino médio os componentes proteção e defesa civil e educação ambiental (Lei n. 12.608, de 2012), entre outras de menor alcance.

Mas além das medidas pontuais cabe destacar dois pontos de maior amplitude. $\mathrm{O}$ primeiro diz respeito à Lei n. 12.796, de 4 de abril de 2013, que, ao ajustar a educação nacional ao disposto na Emenda Constitucional n. 59, de 11 de novembro de 2009, que ampliou a educação obrigatória para a faixa etária dos 4 aos 17 anos, modificou diversos 


\section{Revista HIISTEYIDIR On-line}

dispositivos da LDB. Em consequência, a educação básica obrigatória passou a abranger a pré-escola (4 e 5 anos de idade), ensino fundamental (6 aos 14 anos) e ensino médio (15 aos 17 anos de idade).

O segundo ponto consiste na criação do PRONATEC (Programa Nacional de Acesso ao Ensino Técnico e Emprego), sem dúvida a medida mais significativa do primeiro mandato de Dilma Rousseff relacionada à educação profissional e tecnológica. $\mathrm{O}$ referido programa foi instituído em 26 de outubro de 2011 mediante a sanção da Lei n. 12.513 pela presidenta Dilma Rousseff, tendo como objetivo oferecer cursos de educação profissional e tecnológica para a população, de forma gratuita, para trabalhadores, estudantes e pessoas em vulnerabilidade social, com direito a auxílio alimentação, auxílio transporte e material escolar. Para tanto se propôs a expandir a oferta de cursos de Educação Profissional e Tecnológica (EPT) prevendo uma série de subprogramas, projetos e ações de assistência técnica e financeira, destacando-se: Bolsa-Formação; Fundo de Financiamento Estudantil Técnico (Fies Técnico); Rede e-Tec Brasil; Brasil Profissionalizado; Redes Estaduais de EPT; Rede Federal de EPT.

O subprograma Bolsa-Formação previu a oferta de vagas em cursos técnicos de Formação Inicial e Continuada (FIC) gratuitamente a trabalhadores, estudantes e pessoas em vulnerabilidade social. Trata-se de cursos presenciais oferecidos principalmente pela Rede Federal de Educação Profissional, Científica e Tecnológica, por escolas estaduais de EPT e por unidades do chamado "Sistema S". Há dois tipos de Bolsa-Formação: a Bolsa-Estudante e a Bolsa-Trabalhador. Em ambos os casos, os beneficiários terão direito a cursos gratuitos e de qualidade, a alimentação, a transporte e a todos os materiais escolares necessários que possibilitarão a posterior inserção profissional dos beneficiários.

Nesse contexto, merece destaque a expansão da Rede e-Tec Brasil (Decreto n. 7.589, de 26 de outubro de 2011), que amplia e democratiza a EPT por intermédio da oferta de cursos a distância a partir de centenas de polos pelo país inteiro.

Além disso, previu-se a expansão da Rede Federal de Educação Profissional, Científica e Tecnológica com novos campi em todas as unidades da Federação passando de 140 campi em 2002 para 562 até 2014.

Como assinalei no livro Da LDB (1996) ao novo PNE (2014-2024): por uma outra política educacional, de modo geral pode-se considerar que o PRONATEC constituiu uma iniciativa importante na direção da expansão da oferta de educação profissional e tecnológica, mas padece de pelo menos duas limitações: a crença empiricamente infundada de que há carência de profissionais de nível médio e que, consequentemente, os profissionais desse nível teriam maiores chances de serem absorvidos rapidamente pelo mercado de trabalho; e o incentivo à iniciativa privada alocando recursos públicos para a expansão das vagas oferecidas pelas redes de escolas particulares inclusive aquelas com fins lucrativos. (SAVIANI, 2016b, p. 160). No referido livro, os leitores poderão encontrar uma análise mais 
ampla das medidas de política educacional desde o Governo FHC até o Governo Dilma, além de terem acesso, na forma de anexos, ao teor integral dos documentos legais que embasaram as referidas medidas.

\section{CONCLUSÃO: O GOLPE JURÍDICO-MIDIÁTICO-PARLAMENTAR DE 2016 E OS RETROCESSOS NA EDUCAÇÃO}

O primeiro mandato de Dilma se encerrou no final de 2014 com o novo Plano Nacional de Educação já aprovado pela Lei n. 13.005, de 25 de junho do mesmo ano. E a reeleição da presidenta obtida nas eleições de outubro permitia manter a expectativa de continuidade da política educacional então em curso. No entanto, exatamente quando se alimentou a esperança de algum avanço mais significativo com a aprovação do novo PNE, que finalmente incorporou a meta de $10 \%$ do PIB para a educação, reivindicada desde a década de 1980 por ocasião da Constituinte, e com a destinação de parcela considerável dos recursos do pré-sal para a educação, sobreveio o golpe e estamos diante de um retrocesso não de anos, mas de décadas, incidindo sobre vários aspectos a começar pelo próprio Plano Nacional de Educação que, com a instalação do governo ilegítimo, antipopular e antinacional, resultou totalmente inviabilizado.

De fato, várias metas do PNE já venceram sem serem atingidas. E as demais, cujos vencimentos se distribuem até o limite final dos dez anos de sua vigência em junho de 2024, também já se encontram inviabilizadas pela Emenda Constitucional que o governo fez aprovar no Congresso limitando, por 20 anos, os gastos públicos apenas ao índice de inflação do ano anterior.

Mas além da inviabilização das metas do PNE, outras medidas vêm neutralizando os limitados avanços dos governos Lula e Dilma. Retomando o espírito autoritário vigente na ditadura militar, o governo golpista baixou a reforma do ensino médio mediante Medida Provisória. Como responsáveis pelo Ensino Médio, conforme dispõe a LDB em vigor, os estados e o Distrito Federal deveriam ser consultados sobre a proposta de reforma desse nível de ensino. No entanto, nem mesmo foram informados, sendo surpreendidos com a entrada em vigor da referida reforma uma vez que, sendo baixada por medida provisória, passou a valer imediatamente após sua promulgação.

Logo que foi promulgada a medida provisória foi alvo de uma avalanche de críticas provenientes do Fórum Nacional de Educação, dos Conselhos e Secretarias estaduais de educação, assim como de diversas entidades representativas dos profissionais da educação.

No entanto, o governo, em lugar de levar em conta as críticas revendo a orientação impressa à reforma, ignorou-as e lançou uma agressiva campanha publicitária com muitas inserções diárias nos meios de comunicação chegando, inclusive, ao desplante de colocar no ar uma propaganda com um indivíduo que afirmava que sua vida mudou quando passou a 
cursar uma escola de tempo integral, o que lhe permitiu entrar na faculdade, obter uma bolsa para se formar engenheiro na Espanha e agora é um profissional reconhecido na Espanha. Ora, então essa é uma propaganda do governo do PT, pois essa pessoa cursou a escola de tempo integral bem antes dessa reforma do ensino médio e, além disso, teria se beneficiado do Programa "Ciência sem Fronteira" para obter a bolsa e estudar na Espanha. Mas a população, de modo geral, não faz essa ilação e acaba sendo induzida a acreditar que esse governo a está favorecendo.

Enfim, entre as várias medidas autoritárias que vêm sendo encaminhadas nesse contexto pós-golpe encontra-se o famigerado projeto "escola sem partido" que, proclamando a neutralidade da educação diante da política, busca estimular o idealismo dos professores fazendo-os acreditar na autonomia da educação em face da política, o que os fará atingir o resultado inverso ao que estão buscando: em lugar de preparar seus alunos para atuar de forma autônoma e crítica na sociedade, estarão formando para ajustá-los à ordem existente e aceitar as condições de dominação às quais estão submetidos. Eis por que a "escola sem partido" se origina de partidos situados à direita do espectro político com destaque para o PSC (Partido Social Cristão) e PSDB secundados pelo DEM, PP, PR, PRB e os setores mais conservadores do MDB. Como se vê, a "escola sem partido" é a escola dos partidos da direita, os partidos conservadores e reacionários que visam manter o estado de coisas atual com todas as injustiças e desigualdades que caracterizam a forma de sociedade dominante no mundo de hoje.

Cumpre, pois, ampliar a organização e a mobilização contra o governo ilegítimo, antipopular e antinacional em termos gerais e, especificamente, no campo educacional dando efetividade ao Programa Mínimo lançado pela Frente Brasil Popular e reforçando as iniciativas do Fórum Nacional Popular de Educação por meio da resistência ativa que propus na conclusão do livro sobre a LDB. (SAVIANI, 2016a, p. 303-307).

\section{REFERÊNCIAS}

BRASIL. Constituição (1988). Emenda constitucional no 9 de 9 de novembro de 1995. Lex: Legislação federal e marginaria, São Paulo. Art. 207.

BRASIL. "Lei no 9.448, de 14 de março de 1997”. Brasília: Diário Oficial da União, 15 de março de 1997 - edição extra.

FERNANDES, F. Nova República? 2. ed. Rio de Janeiro: Jorge Zahar, 1986.

FIORI, J. L. "Globalização, hegemonia e império". In: TAVARES, M. da. C.; FIORI, J. L. (Org.). Poder e dinheiro: uma economia política da globalização, 6. ed. Petrópolis: Vozes, 1998.

PUNIR a farsa. Folha de S. Paulo, São Paulo, 15 mar. 1997. Editorial, Caderno 1, p. 1. 
RIBEIRO, D. "Velha e sábia serpente” (Entrevista). Presença Pedagógica. v. 2, n. 8, p. 5 13, mar./abr. 1996.

SAVIANI, D. A lei da educação (LDB): trajetória, limites e perspectivas. 13. ed. rev., atual. e ampl. com um novo capítulo. Campinas: Autores Associados, 2016a.

SAVIANI, D. Da LDB (1996) ao novo PNE (2014-2024): por uma outra política educacional, 5. ed. rev., atual. e ampl. Campinas: Autores Associados, 2016 b.

SAVIANI, D. PDE - Plano de desenvolvimento da educação: análise crítica da política do MEC. Campinas: Autores Associados, 2009.

Notas

\footnotetext{
${ }^{1}$ Professor Emérito da UNICAMP, Pesquisador Emérito do CNPq, Coordenador Geral do HISTEDBR e Professor Titular Colaborador Pleno do Programa de Pós-Graduação em Educação da UNICAMP.

${ }^{2}$ Helmut Kohl foi líder da CDU (União Democrata-Cristã), partido conservador que, em 1982, venceu o SPD (Partido Social-Democrata) ficando no poder até 1998. Após um breve interstício de 7 anos em que retornou ao poder o SPD, a CDU reassumiu o governo da Alemanha em 2005 com Ângela Merkel, reeleita em 2013 para um novo mandato.
}

Submetido em: $25 / 06 / 2018$

Aprovado em: 25/06/2018

Publicado em: 28/06/2018 